\title{
7 Access to Protection under the EU acquis
}

THE RULES REGULATING ACCESS to material protection are the final filtering device in protection systems. Such protection may take many forms, ranging from formal refugee status under the 1951 Refugee Convention to de facto toleration. This chapter deals with two different manifestations of protection. One is the formal granting of some form of protected status; the other is mere non-return. Thus we shall proceed in two steps. First, those parts of the acquis that have an impact on the granting of a formal protection status shall be scrutinised. Second, we shall look into norms of the acquis regulating the return of rejected protection seekers.

\subsection{Protection Categories}

Rationally, one would expect that all Member States should answer the questions 'who is a refugee?' or 'who is a beneficiary of extraterritorial protection?' in roughly the same manner. Three reasons support such an expectation.

First, all Member States are State Parties to the 1951 Refugee Convention, to the ECHR and to CAT. To be sure, the paramount 


\section{CHAPTER 7}

importance of landmark instruments in the field has been acknowledged by the EU Council, when it made clear that the 1951 Convention as well as the 1967 Protocol are part of the EU acquis in the fields of Justice and Home Affairs. The European Convention on Human Rights (ECHR) has been endowed the same status; accession to it now forms a precondition for the admittance of candidate countries into the Union. Protocols Nos 4,6 and 7 to the ECHR also form part of the acquis, but merely on a nonobligatory basis. ${ }^{707}$

The 1951 Refugee Convention, the 1967 Protocol and the ECHR have been qualified as 'inseparable from the realisation of the Union's objectives', and, consequently, states aspiring for Union membership must have acceded to them before admission. ${ }^{708}$ Their guiding function has also been acknowledged in a number of instruments pertaining to the acquis as well as in the foundational treaties. ${ }^{709}$ Identical legal obligations under international law, one would believe, should lead to largely converging protection categories.

Second, a requirement of harmonisation also flows from the operation of the Dublin Convention. As expounded above, this instrument denies a claimant the possibility of choosing between different countries of asylum in the EU. From the perspective of the claimant, predictability and equality in treatment requires that Member States operate protection categories under international law with an identical material scope. ${ }^{710}$

${ }^{707}$ It should be noted though, that the ECHR and its protocols do not figure under the heading of asylum in the Draft List of the acquis, but rather under the less specific heading of human rights. Draft List, p. 31, para. XII. A. b. and D. Protocols 4, 6 and 7 to the ECHR are considerered as instruments which have not all been signed and/or ratified by all Member States, and the Member States are not mutually bound to ratify them, although in the case of some of them there is a political commitment by their Governments to initiate the internal process of ratification. States applying to join the European Union should endeavour to become parties to these Conventions on the same basis as the Member States'. Ibid., Introduction. Protocol 6 is of special interest in this context, as it contains a provision on the abolishment of the death penalty in Art. 1. See also Final Act of the Treaty of Amsterdam, Declaration on the Abolition of the Death Penalty, CONF 4007/97, AF/TA/en2.

${ }^{708}$ Draft List, p. 7, para. I. A. b.

709 See Art. 63 (1) TEC, Art. 6 (2) TEU.

710 This was acknowledged in a discussion paper on subsidiary protection prepared by the Danish delegation for the EU Council. Note by the Danish delegation to the Migration and Asylum Working Parties, 'Subsidiary Protection', Doc. No. 6746/97 ASIM 52 (17 March 1997). 
Third, a high degree of convergence would also flow from a purely theoretical point of view. The rationale of harmonised protection categories is to counter an evolving market mechanism, where states compete for minimised reception by means of restricting the categories of beneficiaries. Such competition would be detrimental not only for persons in need of protection, but also for the interest of those Member States whose burden of reception is increased by their more successful competitors.

For all these reasons, it is hardly surprising that the Commission's 1994 Communication on Asylum and Immigration Policy identified three subjects of harmonisation. The first is the refugee definition, the second relates to 'policies concerning those who cannot be admitted as refugees, but whom Member States would nevertheless not require to return to their country of origin in view of the general prevailing situation in that country' and the third to temporary protection. ${ }^{71}$

However, reality defies theory. In the Union, protection categories are far from being harmonised. The most striking indications are delivered by statistics on recognition rates. Among Member States, recognition rates for Convention refugee status range between 0.7 percent (Finland) to 29.6 percent (Italy) in $1998 .^{712}$ This is astonishing, as the beneficiaries of this status have been defined in the 1951 Refugee Convention. ${ }^{713}$ Adding recognitions under humanitarian status to those for Convention refugees, the percentages stretch from 5.3 (Austria) to 54.5 (Denmark). ${ }^{714}$ The term 'humanitarian status' is not defined in international law, which makes the divergence among Member States somewhat easier to explain.

Still, these divergences may also stem from the fact that different Member States are 'confronted with different groups of protection seekers. Within these groups, actual protection needs can vary to a great extent. Naturally, this may result in diverging recognition rates. Therefore, let us narrow our perspective and look at the recognition rates of a specific

\footnotetext{
711 European Commission, Communication from the Commission to the Council and the European Parliament on Immigration and Asylum Policies, COM/1994/23Final, 23 February 1994, p. 42, paras 6, 8 and 9.

712 UNHCR, 1999, p. 72.

${ }^{713}$ In a survey including inter alia ten EU Member States, it emerged that Germany and the Netherlands had not incorporated the refugee definition in Art. 1 (A) (2) GC into their domestic legislation. See IGCARMP, 1997, p. 437.

714 UNHCR, 1998 Statistical Overview, p. 73.
} 


\section{CHAPTER 7}

group throughout the Union. The aggregate numbers of asylum applications in Europe in the period 1989-98 show that the Federal Republic of Yugoslavia takes the top position among countries of origin. ${ }^{715}$ The recognition percentages of Yugoslav citizens granted Convention status or granted humanitarian status between 1989 and 1998 vary by some fifty percent among Member States. While Spain takes the bottom position with an overall recognition rate of 3.1 percent, Finland tops the list, recognising 53 percent of all applicants under one of the named statuses. Shifting protection needs within the group of Yugoslav asylum applicants can account for certain differences among recognition rates, but hardly for differences of such magnitude. Therefore, it must be concluded that the interpretation of the 1951 Refugee Convention and the protective scope of humanitarian status in domestic law vary to a substantial degree among Member States. ${ }^{716}$

With regard to the interpretation of the refugee definition, this conclusion has been confirmed by comparative research on Member States' domestic approaches. ${ }^{717}$ According to the most recent study, the internal law of the Member States diverges with regard to the origins of persecution, the phenomenon of 'refugies sur place', the relationship of the subjective and the objective element in the Convention definition and the understanding of its five grounds of persecution. ${ }^{718}$

Drawing on the three reasons for convergence developed above, and developing the insights of the Commission further, one may state the following. A successful harmonisation of protection categories needs to fulfil three basic requirements: it has to be all-encompassing, binding and precise. It will not do to harmonise some categories, while leaving others to the free interplay of forces. Therefore, in line with the Commission's

715 The following percentages are calculated on the basis of statistics made available in UNHCR, 1999, pp. 82-4.

716 The question why recognition rates differ may be explained in part by the consequences of non-recognition. In some Member States, the probability of removal upon nonrecognition is rather high; in others, it is lower. It is reasonable to assume that the probability of removal impacts on the mind-set of the decision-maker. Thus, return policies and recognition rates must be analysed together.

717 See inter alia Carlier, Vanheule, et al., 1997 and M. Wolter, Auf dem Weg zu einem gemeinschaftlichen Asylrecht in der Europäischen Union. Rechtsvergleichende Betrachtung des materiellen Asylrechis der EU-Mitgliedstaaten im Hinblick auf eine Vergemeinschaftung der Materie (1999, Nomos Verlagsgesellschaft, Baden-Baden).

718 Wolter, 1999, p. 536. 
1994 Communication, the harmonisation of categories has to cover not only the 1951 Refugee Convention, but also subsidiary protection and temporary protection. Furthermore, any legal instrument purporting to create uniform definitions of beneficiaries must be formally binding as such. And, finally, the categories defined in it need also to be sufficiently concrete and devoid of any deference to national law in order to be effective.

\subsubsection{The EU Acquis Related to Protection Categories: Questions of Scope}

How has the harmonisation process handled the divergence of protection categories in the EU? Starting out with the Convention refugee category, an attempt to come to terms with the disparity in interpretation among Member States was made in 1996 with the non-binding

O Joint Position Defined by the Council on the basis of Article K.3 of the Treaty on European Union on the harmonized application of the definition of the term 'Refugee' in Article 1 of the Geneva Convention of 28 July 1951 relating to the status of refugees. ${ }^{719}$

The very existence of the Refugee Joint Position is evidence that Member States wish to avoid an evolving spiral of restriction in defining refugees. It is all the more lamentable that this effort has to fail even on purely formal grounds. A mere look at paragraph 3 in the preamble confirms that Member States were not in a position to revamp their domestic asylum systems for the sake of harmonisation:

This joint position is adopted within the limits of the constitutional powers of the Governments of the Member States; it shall not bind the legislative authorities or affect decisions of the judicial authorities of the Member states.

719 OJ (1996) L 63, p. 2. 


\section{CHAPTER 7}

Whatever the mandatory force of a Joint Position may be, this paragraph clearly indicates the non-binding nature of the definitional efforts enshrined in the instrument. ${ }^{720}$

The acquis does not contain an instrument harmonising the category of subsidiary protection. ${ }^{721}$ Moreover, the discourse on temporary protection has indicated that Member States have been reluctant to define categories of beneficiaries of such an order. This reluctance is expressed quite unambiguously in the 'Council Resolution of 25 September 1995 on Burden-Sharing with Regard to Admission and Residence of Displaced Persons on a Temporary Basis of 25 September 1995' ${ }^{\prime}{ }^{722}$ Its personal scope comprises various categories of vulnerable persons 'whom Member States are prepared to admit on a temporary basis under appropriate conditions in the event of armed conflict or civil war, including where such persons have already left their region of origin to go to one of the Member States'. ${ }^{723}$ Clearly, these categories must be taken as mere examples without any definite character. The European Commission's proposal for a 'Joint Action on Temporary Protection' ${ }^{\text {'24 }}$ uses the same technique of exemplifying rather than defining. Article 1 of this proposal contains a non-exhaustive list of beneficiary groups, at best serving inspirational purposes. Article 3 regulates how a temporary protection regime is initiated in a given situation. A relevant Council decision shall also determine the groups of beneficiaries. This solution may be characterised as an ad hoc harmonisation of protection categories. While it retains a great margin of discretion for Member States in picking and choosing categories of beneficiaries for a given Temporary Protection regime, Article 3 of the Proposal has the advantage of blocking the spiral of restriction for the period after the launching of the regime.

720 Apparently, the cited paragraph was inserted on the initiative of the British and German delegations. See van der Klaauw, 1997a, p. 240.

721 However, paragraph 4 of the 1997 Unaccompanied Minors Resolution acknowledges that the ECHR and the Convention against Torture and Other Cruel, Inhuman or Degrading Treatment or Punishment, 10 December 1984, 1465 UNTS 85 [hereinafter CAT] may have a bearing on the removal of unaccompanied minors.

722 OJ (1995) C 262/1.

${ }^{723}$ Ibid., Art. 1(a).

${ }^{724}$ Amended proposal for a Joint Action concerning temporary protection of displaced persons (presented by the Commission pursuant to Article 189a(2) of the EC Treaty), COM(1998) 372 final/2, OJ (1998) C 268. 
In conclusion, neither the requirement of all-encompassing harmonisation nor the requirement of bindingness has been satisfied hitherto.

\subsubsection{The Substantial Content of the Refugee Joint Position}

Earlier, we identified definitional precision as a necessary ingredient in the project of harmonising protection categories. Let us now look at the sole achievement of category harmonisation, the Refugee Joint Position, and contemplate some of its material implications. Indeed, the Refugee Joint Position is a comprehensive instrument, albeit it generally maintains a rather high level of abstraction. It contains norms on the individual or collective determination of refugee status, the establishment of evidence, the content of the term 'persecution', the origins of persecution and the grounds underlying it, relocation within the country of origin, the phenomenon of becoming a refugee sur place, conscientious objection and related practices, as well as cessation and exclusion clauses.

Fully in line with its non-binding nature, the harmonising effect of the Joint Position has been low. None of the Member States has amended its legislation, with the exception of Sweden, which amended it along its own statement for the Council minutes, made in connection with the adoption of the Refugee Joint Position. ${ }^{725}$ In the 1998 Council Survey, Member States also quote examples where their law or practice maintains more inclusive positions than those offered by the Refugee Joint Position. ${ }^{726}$ It must be recalled that the stark divergence in recognition rates quoted earlier was based on the 1998 statistics. ${ }^{727}$ This divergence mirrors a situation as it existed two years after the adoption of the Refugee Joint Position.

At least with respect to two important issues, the Joint Position fails to offer sufficiently precise guidance. These issues happen to be of utmost practical importance for delimiting the scope of protection offered by the 1951 Refugee Convention. One is the question of the extent to which the

\footnotetext{
7251998 Council Survey, p. 57.

7261998 Council Survey, pp. 58-9 and p. 65. France and Ireland do not apply the concept of an internal flight alternative, as related to in para. 8 of the Refugee Joint Position. Belgium, Ireland, Austria and Sweden profess to operate a broader concept of persecution by third parties. On the latter aspect, see text accompanying note 729 below.

727 See text accompanying note 712 above.
} 


\section{CHAPTER 7}

1951 Refugee Convention offers protection to the victims of persecution by third parties. ${ }^{728}$ Given the increasing number of persecutory acts carried out by non-state actors, this issue is of enormous numerical importance. The other is the question of whether and when protection can be denied with reference to an internal flight alternative.

When pondering this issue, the following situations must be kept apart:

1. persecution by state agents;

2. acquiescence by state agents of persecution carried out by non-state agents; and

3. incapacity of state agents to hinder persecution carried out by nonstate agents.

Cases of direct violations under the first and second category are rather unproblematic in this context, while the third category represents the focal point of the dispute on persecution by third parties. Precisely as in the second category, violations are committed by private actors. Differently from the second category, however, the state is simply unable to protect. In extreme cases, the inability to control is due to the vanishing of state structures altogether.

A comparative analysis commissioned by the Dutch Ministry of Foreign Affairs concludes that for Canada, the U.K., Sweden, Italy, and the Netherlands' District Court governmental complicity in persecution is inessential, while the opposite is true for Germany, Switzerland, France and the Netherlands Council of State. ${ }^{729}$

The Refugee Joint Position mirrors the difference in interpretation between individual Member States in a very graphic fashion. To start with, paragraph 5.2 of the Refugee Joint Position states that:

Persecution by third parties will be considered to fall within the scope of the Geneva Convention where it is based on one of the grounds in Article 1A, is individual in nature and is encouraged or

${ }^{728}$ See the criticism voiced in UNHCR, Expresses Reservation over EU Asylum Policy, Press Release, 24 November 1995; and in ECRE, Note from the European Council on Refugees and Exiles on the Harmonization of the Interpretation of Article 1 of the 1951 Geneva Convention, June 1995.

729 B. Vermeulen, T. Spijkerboer, K. Zwaan and R. Fernhout, Persecution by Third Parties (1998, University of Nijmegen/Centre for Migration Law, Nijmegen), p. 34. 
permitted by the authorities. Where the official authorities fail to act, such persecution should give rise to individual examination of each application for refugee status, in accordance with national judicial practice, in the light in particular of whether or not the failure to act was deliberate. The persons concerned may be eligible in any event for appropriate forms of protection under national law.

This wording was the result of a French compromise proposal, mediating between inclusionary and exclusionary positions. ${ }^{730}$ It suggests deliberateness in state failure to act as the guiding criterion. Does this imply that persecution by third parties not 'permitted' by the state is excluded from the protective ambit of the 1951 Refugee Convention? One reading would be that such cases are indeed excluded. The establishment of a guiding criterion appears meaningless if free choice between inclusion under and exclusion from the scope of the 1951 Refugee Convention was intended to continue. But it could also be argued that the wording does not expressly inhibit states to include such cases under the scope of the 1951 Refugee Convention. Thus, the intention with paragraph 5.2 would be to include at least direct and indirect forms of state persecution. This interpretation would point to the phrase 'in accordance with national judicial practice' in the second sentence and 'in any event' in the third sentence as indicators of a discretionary margin. The fact that paragraph 5.2 condones the existence of irreconcilable interpretations of the refugee definition is most problematic from an integration perspective. As a U.K. Court succinctly stated, the Refugee Joint Position is, indeed, an 'agreement to disagree'. ${ }^{731}$

However, one Member State felt the need to express that the third category may very well be included under the scope of the 1951 Refugee Convention. In a statement for the Council Minutes, the Danish and Swedish delegations declared themselves to be

of the opinion that persecution by third parties falls within the scope of the 1951 Geneva Convention where it is encouraged or permitted by the authorities. It may also fall within the scope of

${ }^{730}$ For the drafting history of the Refugee Joint Position, see Vermeulen, Spijkerboer, Zwaan and Fernhout, 1998, pp. 31-2.

${ }^{731}$ U.K. Court of Appeal (Civil Division), $R$ vs SSHD ex parte Adan and others, 23 July 1999, [henceforth Adan and others], para. 74. 


\section{CHAPTER 7}

the Convention in other cases, when the authorities prove unable to offer protection. ${ }^{732}$

This manifest divergence explains the limited harmonisation potential of the Refugee Joint Position. It gives rise to concern, though, that a restrictive position gained entry into the document, while the inclusive position was relegated to a mere interpretatory statement. The least that can be said about the Refugee Joint Position is that it offers a presumption for the exclusion of cases under the third category. We will be compelled to return to the issue of persecution by third parties in a later chapter of this work. ${ }^{733}$

\subsubsection{Competencies after Amsterdam}

Article 63 (1) (c) TEC provides an EC competence to harmonise the interpretation of the Convention refugee definition. It stipulates that, within five years after the entry into force of the Treaty of Amsterdam, the Council shall adopt:

(1) measures on asylum, in accordance with the Geneva Convention of 28 July 1951 and the Protocol of 31 January 1967 relating to the status of refugees and other relevant treaties, within the following areas:

[...]

(c) minimum standards with respect to the qualification of nationals of third countries as refugees.

The Action Plan merely confirms the time-frame of five years. ${ }^{734}$ It is worth noting that the wording limits the EC competency to 'nationals of third countries', thus amplifying the questionable exclusionary approach with regard to EU citizens taken in the Spanish Protocol.

However, EC competencies are not exhausted with this entitlement. Article 63 (2) (a) TEC provides a legal basis for the Council to discuss the harmonisation of both subsidiary protection categories and temporary

\footnotetext{
732 Statement for the Council minutes, attached to the Refugee Joint Position.

${ }^{733}$ See chapter 12.2.2 below.

734 Action Plan, para. 38 (b) (i).
} 
protection practices. This provision stipulates that the Council shall adopt, within the transitional period of five years,

(2) measures on refugees and displaced persons within the following areas:

(a) minimum standards for giving temporary protection to displaced persons from third countries who cannot return to their country of origin and for persons who otherwise need international protection

A careful reading indicates that this provision actually covers two groups for which certain minimum standards shall be devised. ${ }^{735}$ One would contain certain displaced persons from third countries. This group would be given temporary protection. The other group would consist of persons who otherwise need international protection. The protection to be accorded to them is not qualified in the quoted provision. The nonbinding Action Plan envisages that measures '[d]efining minimum standards for subsidiary protection to persons in need of international protection (Article 63(2) (a) second part) ${ }^{373}$ shall be adopted by the Council within five years after the entry into force of the Amsterdam Treaty. It should be noted that there is no express reference to the qualification of beneficiaries as in Article 63 (1) (c) TEC. Moreover, the Action Plan only alludes to standards enjoyed by the beneficiaries of subsidiary protection, and is tacit on the issue of qualifying those beneficiaries. It could be argued that Article 63 (2) (a) TEC would allow for the EC institutions to adopt such a definition, without laying down an obligation to do so.

As a consequence of a Danish initiative within the Council, a questionnaire on protection subsidiary to the 1951 Refugee Convention

735 This reading is supported by the wording of the provision, which relates to 'minimum standards for giving temporary protection to displaced persons [...] and for persons who otherwise need international protection' (emphasis added). For a detailed argumentation drawing on the different language versions of the TEC, see G. Noll and J. VedstedHansen, 'Temporary Protection and Burden Sharing: Conditionalising Access, Suspending Refugee Rights?', in E. Guild and C. Harlow (eds), Implementing Amsterdam, Immigration and Asylum Rights in EC Lawe (2000, Hart, Oxford), (page numbers were not available at the time of writing).

736 Para. 38 (b) (ii) Action Plan. 


\section{CHAPTER 7}

has been circulated amongst Member States. ${ }^{737}$ Moreover, a study on the same subject has been undertaken by the Secretariat of the Council. ${ }^{738}$ It is still too early to predict the outcome of this initiative. The Council is also preparing an instrument on temporary protection, which, however, largely relies on an ad-hoc determination of beneficiaries. Proposals discussed in 1999 suggest that no abstract definition is envisaged. ${ }^{739}$

\subsubsection{Conclusion}

Harmonisation in the field of protection categories is neither comprehensive, nor binding, nor precise. The market dynamics tempting states to limit recognition under the relatively favourable Convention category remains largely unchecked. For the functional reasons expounded above, the present state of affairs is clearly dissatisfying, as continued divergence between protection categories may effectuate reception inequalities between Member States as well as protection differences for individuals. It follows that future co-operation needs to widen the scope of harmonisation from the refugee definition to other categories and has to be given a binding and concrete form devoid of exceptions.

\subsection{Return}

Throughout the last decade, individual Member States have sought ways and means to render their domestic return policies more effective. The domestic legislation of all Member States features the principle that undocumented aliens-of which rejected protection seekers form a

${ }^{737}$ Note from the General Secretariat of the Council to the Migration and Asylum Working Parties, Summary of replies concerning the national instruments of protection falling outside the scope of the Geneva Convention-Subsidiary protection, Doc. No. 13667/97 ASIM 267 (6 January 1998).

${ }^{738}$ Note from the General Secretariat of the Council to the Migration and Asylum Working Parties, Study on the international instruments relevant to subsidiary protection, Doc. No. 10175/98 ASIM 178 (13 July 1998).

739 One of the 1999 Council drafts suggests that it would be for the Council to decide 'the specific group of persons to which the temporary protection regime applies'. European Council, Draft Joint Action concerning temporary protection of displaced persons, 16 February 1999, Doc. No. 5682/1/99 REV1, Art. 3 (3) (a). 
fraction-ultimately are under an obligation to leave state territory. Beyond this convergence in principle, 'there is no uniform application of return policy ${ }^{740}$ in the Union.

The reasons for factual divergences among Member States are manifold. First, it must be recalled that the issue of return articulates itself differently in the individual member states. Those who have functioned as countries of destination for some time have been confronted with return issues for a longer period (e.g. Germany and the Scandinavian Member States) than those who have only recently shifted from the role of a transit to that of a destination state (e.g. Italy or Spain). The geographical situation, political ties to third countries and the existence of domestic immigrant communities may all impact upon the specifics of a Member State's return policy. Secondly, stringent return practices require considerable financial, personal and organisational resources-either by creating incentives or by enforcing compliance. Allocating these resources is a matter of available means and political will. Member States differ in the amount of resources earmarked for return purposes. While all of them agree on the importance of return in the abstract, the degree of concrete political commitment is highly individual.

One example is the negotiation of bilateral readmission agreements with countries of origin to render return more effective. While the use of these agreements is rather widespread amongst Member States, there are considerable differences as to the number of agreements negotiated, the countries targeted, the technical solutions chosen and the financial or other benefits linked to the conclusion of such agreements.

So far, EU co-operation reflects an aspiration to increase harmonisation of return policies and practices. This can be derived from the impressive number of EU instruments related to return. However, these instruments have by no means created a harmonised Union-wide approach to return. Technically, the majority of instruments adopted are non-binding, and the monitoring of their implementation is undeveloped. ${ }^{741} \mathrm{~A}$ more

${ }^{740}$ State Secretary Cohen's Note on the Dutch Return Policy, Ministry of Justice [The Netherlands], 25 June 1999, section 1.

${ }^{741}$ Evaluating the asylum and immigration acquis achieved before Amsterdam, the Council has confirmed this criticism: 'However, the instruments adopted so far often suffer from two weaknesses: they are frequently based on "soft law", such as resolutions or recommendations that have no legally binding effect. And they do not have adequate monitoring arrangements'. Amsterdam Action Plan, para. 8. 


\section{CHAPTER 7}

comprehensive explanation would be that return is probably the most sensitive area in the construction of a state's demos. Hitherto, Member States have simply not been prepared to compromise their sovereignty in this respect. Thus, co-operation in the Council has not altered the array of diverging domestic practices among the Union's Member States.

Notwithstanding these considerations, the need for a co-ordinated approach to return has been consistently stressed within the EU framework. The Commission's 1994 Communication on Immigration and Asylum Policies identified the repatriation of those who are found to be in an irregular situation to be one of four key elements in the countering of illegal immigration. ${ }^{72}$ Although the Council has yet to adopt a strategy on migration and asylum issues, a recent position posits return as an important element of a comprehensive policy, underscoring the importance of expulsion, readmission agreements, voluntary return and reintegration. ${ }^{733}$

Generally, in the return policies of destination states, five different considerations can be discerned, which will be briefly presented in the following. ${ }^{74}$ A primary consideration of return policies is to ensure the individual's voluntary compliance with the obligation to leave the host country. Promotion of voluntary return ranges from simple measures informing on the situation in the country of origin to programmes involving financial assistance. Concerning the latter, states are usually anxious not to create unintended incentives, where return assistance would attract further migrants. ${ }^{75}$

${ }^{742}$ The other elements are the prevention of entry, the identification of persons illegally resident and the definition of minimum standards of treatment for such persons. Commission of the European Communities, Communication from the Commission to the Council and the European Parliament, 23 February 1994, COM(94) 23 final, paras 111-7.

${ }^{743}$ Council of the European Union, Guidelines for a European Migration Strategy, 1 June 1999, Doc. No. 8815/99 ASIM 23, para. 28.

${ }^{744}$ For a comprehensive overview on the issue of return and a case study on Germany, see G. Noll, Responding to the Arrival of Asylum Seekers. Unsucessful Asylum Seekers-The Problem of Return (1998, Geneva), United Nations ACC Task Force on Basic Social Services for All (BSSA), Working Group on International Migration.

${ }^{745}$ See the sixth recital in the preamble to the Council of the European Union Decision of 26 May 1997 on the exchange of information concerning assistance for the voluntary repatriation of third-country nationals, OJ (1997) L 147/3: 'Whereas it should be avoided that such assistance leads to undesired incentive effects; $[. .$.$] '.$ 
A second consideration for returning states is to devise measures responding to non-compliance with the obligation to leave under domestic law. Some of these measures are intended to secure the preconditions for removal; they include measures of identification (i.e. by means of fingerprinting, database checks or language tests), documentation (obligations to assist with travel document procurement), localisation (reporting obligations and detention) and, finally, the actual removal (expulsion orders and escorts).

Disputes on nationality, delays in issuing travel documents or an outright denial of readmission by countries of origin may also inhibit efficient return practices. Thus, a third consideration of returning states is to ensure the co-operation of the country of origin.

A fourth consideration is to secure the co-operation of third states in return operations. This may take the form of forming negotiating cartels to exert pressure on recalcitrant countries of origin. To give another example, returning states may also approach potential transit states lying en route on the migratory trajectory in order to negotiate agreements on readmission, or transit, or both.

Finally, a fifth consideration for returning states is to secure a sustainable return. In the individual case, this means alleviating the pressures leading to renewed attempts of undocumented migration. The measures taken vary according to the nature of the emigration pressure. In a wider perspective, this mechanism compels returning states to take an increased interest in the realisation of civic and political as well as economic, social and cultural rights in countries of origin. Ultimately, the returning state assists in the protective tasks of the country of origin.

In the following, we shall look into how these five considerations manifest themselves in the EU acquis as well as in the Schengen acquis.

\subsubsection{The EU acquis Related to Return}

In the EU context, all five categories of return activities listed above have been the subject of continued intergovernmental deliberations. These have resulted in few binding and many non-binding norms. Let us now explore the return acquis along the structure of the five considerations. 


\section{CHAPTER 7}

Regarding the promotion of voluntary return, it is somewhat surprising that the Council did not bother to deal with the most dignified and least costly solution earlier than in $1997^{746}$, when it adopted the

O Council Decision of 26 May 1997 on the exchange of information concerning assistance for the voluntary repatriation of thirdcountry nationals. ${ }^{747}$

This Decision called for the collection of information on Member States' programmes supporting voluntary return for purposes of comparison and dissemination.

The period from 1997 to and including 1999 saw the adoption of experimental instruments that made Community funds available on a yearly basis to facilitate the voluntary repatriation of displaced persons who have found temporary protection in the Member States and asylumseekers. ${ }^{748}$ Formally, these instruments were Joint Actions directed at the Community, and thus legally binding on it. Together with the 1997 Decision, these Joint Actions stand out against the multitude of instruments dealing with implementation of return against the will of the individual.

A considerable number of instruments deal with the second consideration of securing the preconditions of removal and actually carrying it out. From earlier discussion, we recall that the Dublin Convention contains an obligation for State Parties to readmit a rejected asylum seeker who has entered the territory of another State Party without being authorised to reside there, provided that it has not expelled the alien (Article 10 (e) DC). It should be noted that, so far, this norm is the only one in the whole EU asylum acquis that is legally binding upon Member States. Clearly, it provides an incentive for a consistent expulsion strategy, as State Parties want to avoid the responsibilities flowing from the obligation to readmit.

746 Already in its 1994 Communication, the Commission had called for an approximation of voluntary return schemes, underscoring that such schemes are 'cost-effective, when compared with the costs of involuntary repatriation'. Communication to the Council and the European Parliament on immigration and asylum policies, COM (94) 23 final, Brussels 23 February 1994, 30, at para. 111.

747 OJ (1997) L 147/3.

${ }^{748}$ For a detailed presentation, see chapter 8.3 .5 below. See also chapter 8.3 .6 below on the funding of voluntary return projects through the proposed European Refugee Fund. 


\section{ACCESS TO PROTECTION}

Moving on to non-binding instruments, we find that two Recommendations, namely the

- Recommendation of 30 November 1992 regarding practices followed by Member States on expulsion ${ }^{749}$, and the

O Recommendation of 1 June 1993 concerning checks on and expulsion of third-country nationals rèsiding or working without authorization $^{750}$,

spell out the basic rule that persons found to have failed definitively in an application for asylum and to have no other claim to remain should be expelled, unless there are compelling reasons, normally of a humanitarian nature, for allowing them to remain. Two further instruments attempt to mitigate problems with travel document procurement. First, the

O Recommendation of 30 November 1994 concerning the adoption of a standard travel document for the removal/expulsion of thirdcountry foreign nationals $\mathbf{s}^{751}$

recommends Member States to make use of a one-way travel document to facilitate the expulsion of persons lacking the necessary travel documents. ${ }^{752}$ Second, the

- Recommendation of 22 December 1995 on harmonizing means of combating illegal immigration and illegal employment and improving the relevant means of control ${ }^{753}$

states that, in case an alien is, or is likely to be, detained before expulsion, the period of detention should be used to obtain the necessary travel documents for expulsion. ${ }^{754}$

\footnotetext{
749 WGI 1266, reprinted in Guild and Niessen, 1996, p. 219, para. 2.

750 WGI 1516, reprinted in Guild and Niessen, 1996, p. 275, para 1.

751 OJ (1996) C 274/18.

752 For a critical commentary, see Guild and Niessen, 1996, p. 388.

753 OJ (1996) C 5/1.

754 Ibid., para. 10.
} 


\section{CHAPTER 7}

In this area, important normative lacunae remain. Member States have largely failed to address issues related to the rights and interests of rejected asylum seekers. ${ }^{755}$ By way of example, the tragic deportation incidents of 1998 and 1999 have shown that the use of force is insufficiently regulated among Member States. ${ }^{756}$ After the three fatal incidents in connection with forcible removals, the relevant Member States amended their guidelines unilaterally. Interestingly, border police authorities started to make contact with each other spontaneously to compare existing guidelines. $^{757}$ A benevolent observer would find this to be a practical expression of the subsidiarity principle. However, one might also ask if a Council instrument on the use of force during deportation might have contributed to prevent the fatal incidents from happening.

With regard to securing the co-operation of countries of origin, the existing acquis offers further non-binding norms, most of them in the area of readmission. The

O Recommendation of 22 December 1995 of concerted action and cooperation in carrying out expulsion measures ${ }^{758}$

states that Member States should implement specific mechanisms to improve the procurement of the necessary documentation from the consular authorities of the third state to which third-country nationals are

755 This has been observed by the Commission in its 1994 Communication, where it recommended Member States to sign and ratify the International Convention on the Protection of the Rights of All Migrants Workers and Members of their Families, adopted by GA Res. 45/158 (1990). This instrument has a bearing on the matter, as it also covers illegal migrant workers. Up to now, no Member State has followed this suggestion.

756 On 22 September 1998, a rejected Nigerian asylum seeker, Ms. Semira Adamu, died of asphyxia, after Belgian police officers had pressed a cushion in her face during a deportation attempt at Brussels Airport. Less than half a year later, on 1 May 1999, Mr. Marcus Omofuma died during a deportation attempt by the Austrian authorities. His death was caused by suffocation; his mouth had been covered with adhesive tape and he had been tied to his passenger seat. Twenty-eight days later, a rejected Sudanese asylumseeker, Mr. Aamir Ageeb, died due to suffocation during a deportation attempt by German authorities. A full-faced motorcycle helmet had been placed on his head to prevent him form hurting others and himself, and a German border guard held down his head during take-off.

757 Interview with Lieutnant Dirk Beersmans, Dutch Border Police, Zaventem, 6 August 1999.

758 OJ (1996) C 5/3. 
to be expelled when they lack travel or identity documents. ${ }^{759}$ It should also be noted that the instruments of the acquis dealing with readmission agreements have a direct bearing on return of rejected protection seekers, as they also affirm and specify the obligation to take back one's own nationals. We recall that the Council has drafted a bilateral specimen agreement and guidelines for readmission protocols. Moreover, the insertion of readmission clauses into future mixed agreements and Community agreements plays an important role in the return process. These parts of the acquis have been presented earlier. ${ }^{760}$

Finally, the creation of the High Level Working Group on Asylum and Migration (HLWG) in $1998^{761}$ has brought about an interesting institutional change impacting the area of return. The HLWG has been established as an integrated cross-pillar approach targeted at the situation in the most important countries of origin of asylum seekers and migrants. Its task is inter alia to identify these countries and to establish a plan concerning some of them. ${ }^{762}$

Amongst the elements which could be part of such plans, the terms of reference name

a) the insertion of readmission clauses in an association agreement or a mixed agreement or both, ${ }^{763}$ and

b) the conclusion of an EC readmission agreement with the country in question. ${ }^{764}$

Moreover, the HLWG has also been tasked to explore measures aimed at favouring voluntary return to the named countries. ${ }^{765}$

\footnotetext{
759 Ibid. para. 1.

760 See chapter 5.2.2.2 above.

761 The HLWG was established by a Council Decision on 8 December 1998. See Council of the European Union, Terms of reference of the High Level Working Group on Asylum and Migration; preparation of action plans for the most important countries of origin and transit of asylum-seekers and migrants, 25 January 1999.

762 Afghanistan, Pakistan, Albania and the neighbouring region, Morocco, Somalia and Sri Lanka have been selected for the preparation of an action plan. Council of the European Union, Terms of reference of the High Level Working Group on Asylum and Migration; preparation of action plans for the most important countries of origin and transit of asylum-seekers and migrants, 25 January 1999, para. 3.

${ }^{763}$ Ibid, para. 1 (c) (v).

${ }^{764}$ Ibid, para 1 (c) (vi).
} 


\section{CHAPTER 7}

Concerning the co-operation of third states, it should be noted, first, that the whole array of EU instruments adopted in the field and the institution of the HLWG represent an effort to co-operate among the Member States. More specifically, provisions for the transit of removed persons through other Member States are made in the

- Recommendation of 30 November 1992 regarding transit for the purposes of expulsion. ${ }^{766}$

In addition, Member States are recommended to carry out expulsions, in appropriate instances, as a concerted effort with other Member States. ${ }^{767}$ An example of such co-operation is the exchange of information among Member States on available seats on expulsion flights.

Another instrument is dedicated to the monitoring of the return acquis:

O Decision of 16 December 1996 on monitoring the implementation of instruments adopted by the Council concerning illegal immigration, readmission, the unlawful employment of third country nationals and cooperation in the implementation of expulsion orders. ${ }^{768}$

The fifth consideration of securing the sustainability of return has not yet spawned an instrument of its own. However, the terms of reference given to the HLWG indicate that this consideration could be integrated into the action plans regarding single countries of origin, which the group is tasked to draft. On a more general level, the efforts by the EU to promote human rights in third countries by means of its external relations should be named. ${ }^{769}$

\footnotetext{
${ }^{765}$ Ibid, para. 1 (c) (x).

766 WGI 1266. Reprinted in Guild and Niessen, 1996, p. 239.

${ }^{767}$ Conclusion of 4 March 1996, note 600 above, at para. 6.

768 OJ (1996) L 342/5.

${ }^{769}$ For an overview of EC support to democratic transition and human rights, see B. Simma, J. B. Aschenbrenner and C. Schulte, 'Human Rights Considerations in the Development Co-operation Activities of the EC', in P. Alston (ed.), The European Union and Human Rights (1999, OUP, Oxford), pp. 595-614. For a general analysis of the role of human rights in the external relations of the EU, see A. Clapham, 'Where is the EU's Human
} 


\subsubsection{The Schengen acquis Related to Return}

The Schengen acquis adds a few elements, mainly related to securing cooperation among Schengen states, to what has already been elaborated within the Union. The cornerstone is a binding norm: Article $23 \mathrm{SC}$ spells out the principle that an alien without permission to stay on the territory of a State Party must leave the common territories without delay. The same provision obliges State Parties to expel such an alien. ${ }^{770}$ Compared to the Dublin Convention, there is no 'responsibility principle' to the effect that Non-Schengen-nationals are transferred to a Schengen state considered to be responsible for their illegal presence. ${ }^{71}$ In addition, the Schengen Convention comprises a comprehensive information exchange by means of the Schengen Information System (SIS), facilitating inter alia the identification of aliens illegally staying on the territories of State Parties. ${ }^{772}$

Apart from general affirmations on the importance of return ${ }^{773}$, the Schengen Executive Committee has also agreed on specific forms of cooperation. Through a 1998 Decision, the Schengen states agreed on a transit document to be used in connection with the expulsion of foreign nationals by air. ${ }^{774}$ Another decision, taken the same year, attempts to

Rights Common Foreign Policy, and How is it Manifested in Multilateral Fora?', in P. Alston (ed.), The European Union and Human Rights (1999, OUP, Oxford).

770 Art. 23, para. 3 SC.

771 Compare Art. 10 (e) DC. However, Art. 23 para. 2 DC makes an exception for those aliens admissible in other Schengen states: 'An alien who holds a valid residence permit or temporary residence permit issued by another Contracting Party must enter the territory of that Contracting Party without delay'. -At present, a Finnish draft Regulation is discussed in the Council, which aims at establishing readmission obligations between Member States for the readmission of third-country nationals. Initiative of the Republic of Finland with a view to the adoption of a Council Regulation determining obligations as between the Member States for the readmission of third-country nationals, 7 December 1999, OJ (1999) C 353, pp. 6-9.

772 Art. 38 SC.

773 By way of example, the Decision of the Executive Committee of 27 October 1998 on the adoption of measures to fight illegal immigration calls for '[i]mmediate and systematic return of third-country nationals who have entered the Schengen States without authorization provided no right to stay exists and there are no obstacles based on compelling humanitarian grounds or international law' in its para. 12.

774 Schengen Executive Committee, Decision of the Executive Committee of 21 April 1998 on cooperation between the Contracting Parties in returning foreign nationals by air, 21 April 1994. 


\section{CHAPTER 7}

tackle difficulties in document procurement for the purposes of return caused by recalcitrant consulates of the country of origin in Schengen capitals. In such cases, Schengen states have agreed to make use of each others' ambassadors in the country of origin for mounting local pressure there. ${ }^{775}$

\subsubsection{Competencies after Amsterdam}

Return is included in the legislative agenda set by the Treaty of Amsterdam. According to Article 63 (3) (b) TEC, the Council shall adopt measures on 'illegal immigration and illegal residence, including repatriation of illegal residents' within the five-year transitory period.776 According to the Action Plan on the Implementation of the Treaty of Amsterdam, the establishment of 'a coherent EU policy on readmission and return' should be achieved in an even shorter period, namely two years. ${ }^{777}$ Furthermore, the Action Plan confirms that, within a five-year period, 'the possibilities for the removal of persons who have been refused the right to stay through improved EU co-ordination implementation of readmission clauses and development of European official (Embassy) reports on the situation in countries in origin" ${ }^{778}$ is to be improved.

\subsubsection{Assessment of the EU acquis Related to Return}

The assessment of return policies is mainly hampered by the lack of coherent statistics. For many countries, relevant data are simply unavailable. This is all the more surprising, as return has been high on the agenda of asylum countries in the industrialised world. While the number of protection claims as well as recognitions under various categories are

\footnotetext{
775 Schengen Executive Committee, Decision of the Executive Committee of 23 June 1998 on measures to be taken in respect of countries posing problems with regard to the issue of documents required for expulsion from the Schengen territory, 23 June 1998.

776 Art. 63 (3) (b) TEC. Measures adopted under this paragraph do not prevent Member States from maintaining or introducing national provisions that are compatible with the Treaty of Amsterdam and with international agreements.

777 Ibid., para. 36 (c) (ii).

778 Ibid., para. 38 (c) (i).
} 


\section{ACCESS TO PROTECTION}

known and eagerly disseminated ${ }^{779}$, it remains largely obscure how many rejected claimants return voluntarily and how many move on to third countries. ${ }^{780}$

Existing domestic statistics suffer from the absence of a coherent methodology, making Europe-wide comparisons impossible. ${ }^{781}$ However, neither the number of removals nor the number of voluntary departures tells us anything as such. To make sense, they have to be related to the total number of rejected protection seekers. Counting this group involves two problems.

First, there is only a slim chance of specifying the number of those with whom the authorities do not maintain any contact. Have they left for another country? Have they remained in-country? Or did they return home? It is extremely difficult to estimate how many rejectees actually remain in the territory of the state where the determination procedure was carried out.

Second, to provide a base for measuring the efficiency of control policies, only those whose removal is not inhibited by reasons related to protection must be counted. Let us take the example of a person whose asylum claim has been rejected in Germany. Although this person is formally under an obligation to leave, he or she may still benefit from a stay of removal (Duldung). As a decision on stay of removal is based on considerations of protection, this person should not be counted in among the group of removables, as long as the decision on stay of removal remains valid. This example goes to show that the German statistics on undocumented migrants under an obligation to leave cannot be taken as data according to which actual departures can be measured. Before measuring actual departures, that is, categories that cannot be removed due to protection-related considerations must be subtracted. Otherwise, any assessment of efficiency will be distorted.

This lack of information has been acknowledged in a strategy paper drafted by the EU presidency stating that 'the Union is still not able to

779 For a compilation, see UNHCR, Asylum-Seekers and Refugees in Europe in 1998: A Statistical Assessment with a Special Emphasis on Kosovo Albanians (1999, UNHCR, Geneva).

780 This is acknowledged in a strategy document prepared by the Austrian Presidency for the K.4 Committee. Note by the Presidency to the K. 4 Committee, 'A Strategy for Migration and Asylum Policies', Doc. No. ASIM 170 (1 July 1998), at para. 72.

${ }^{781}$ In one country, the number of expulsions might relate to legal decisions, while another will count persons actually removed from its territory. 


\section{CHAPTER 7}

give accurate information regarding the number of third country nationals illegally on the territory of its Member States or exact details of asylumseekers and immigrants who have disappeared to an unknown destination'. ${ }^{782}$ The absence of data is in stark contrast to the existing political rhetoric of return, taking for granted that the numbers are sufficiently high to call the credibility of the asylum system into question. By consequence, it is impossible to assess whether the measures taken by Member States hitherto are efficient or proportional to the importance of the problem.

Apart from inquiring into the magnitude of the return problem, one might also ask whether the strategy taken by Member States is appropriate. To yield maximum effect, which actor should be targeted-the individual, the country of origin, or transit states? In other words, is it self-evident that the reluctance of the individual is at the core of the problem? Of course, the overall lack of statistics prohibits a generalised answer to this question. However, a look at domestic statistics allows us to derive some valuable indications.

A recent paper by the Dutch Ministry of the Interior attempts to identify the scope of the return problem in the Netherlands. ${ }^{783}$ Indeed, the Netherlands is, in some respects, representative. It remains one of the most important destination countries for protection seekers in Europe, and the return of rejected cases has acquired increasing prominence in domestic politics.

As of 1 May 1999, 63116 aliens were registered as inhabitants in the Dutch reception system. Of those, some 58000 persons were seeking asylum or another form of protection. ${ }^{784}$ The remaining 5046 persons were 'removable persons', i.e. persons without any claim for a continued presence on Dutch territory.

Of those 5046 persons, 4013 persons could not be removed due to either political or technical impediments. For the purposes of the Dutch

782 Council of the European Union, Strategy paper on migration and asylum policy, Date unavailable. This paper represents the second revision of the draft of 1 July 1998, and has been officially 'noted' by the JHA Council as a basis for the Union's future migration policy.

783 State Secretary Cohen's Note on the Dutch Return Policy, Ministry of Justice, 25 June 1999. The following presentation of statistics is based on subsections 2 and 3 of the Note.

784 The quoted document states the number of 58000 persons. However, provided that the number of persons not in procedure is identical with the number of removable persons, the exact number of persons in procedure must be 58070 . 
statistics, 'political impediments' means that return is not implemented due to the general situation in the country of origin. As of 1 May 1999, such impediments existed for removal to Afghanistan, Angola, Burundi, the Democratic Republic of Congo, the Federal Republic of Yugoslavia and Rwanda. To be sure, the 779 persons whose return was impeded due to the general situation in their country of origin benefit from a rudimentary form of protection. As refugees and other categories of protected persons are not considered part of the return problem as delimited here, these 779 persons would also fall outside its limits. The reasons inhibiting their return are neither connected to their own recalcitrance, nor to that of their country of origin, but flow from the human rights situation in the latter.

Further, 3084 persons originate from countries to which return is difficult to achieve due to 'technical impediments'. Such impediments are usually connected to the lack of travel documents and difficulties in obtaining them. This group is composed of people of 13 nationalities.

No such impediments existed in the remaining 1033 cases. To conclude, in only about one fifth of the screened cases, is it evident that the implementation of removal can be decisively facilitated by targeting the individual will of the migrant. ${ }^{785}$ In the majority of cases, the critical actor is not necessarily the individual, but rather the country of origin, which retains de facto power over the formal preconditions of return. ${ }^{786}$

Provided the Dutch situation is sufficiently representative of the whole of the EU, the efforts of Member States would first and foremost need to target countries of origin.

As we have seen above, the Union's activities have remained relatively weak in this area, with the majority of instruments relating to the second

${ }^{785}$ Following our reasoning above, these 1033 cases should be contrasted with the total of 4017 cases where return was not barred by reasons related to the human rights situation in the country of origin. This means that the fraction increases to roughly one fourth of the cases in point. - It is of interest that the State Secretary explicitly denies that removable persons go underground to a substantial extent: ' $I$ have no indications that this would be substantially the case'. State Secretary Cohen's Note on the Dutch Return Policy, note 783 above, section 2 . Thus, the conclusion made here is not invalidated by the fact that a large number of removable persons defect from the reception system.

786 This is not to say that the individual's willingness to return is without importance for the actual possibilities of return. In some cases, diplomatic representations issue a travel document for willing return migrants, but refrain from doing so when their citizen is unwilling to return. Nonetheless, such cases show that the ultimate decision on return lies de facto with the country of origin. 


\section{CHAPTER 7}

consideration-securing the preconditions of return-rather than to the third, which concerns securing the co-operation of the country of origin. The latter consideration has been for the most part dealt with unilaterally by certain Member States, and the degree of co-operation or harmonisation has been rather limited. Depending on the outcome of its work, the establishment of the HLWG could represent a paradigm shift, however.

Targeting countries of origin is not an easy task, and the reach of single Member States as well as the EU is limited. As international relationships are based on the sovereign equality of states, it is obvious that a sensitive approach is needed. Compared to securing the co-operation of countries of origin, targeting individuals is of secondary importance. Notwithstanding this, it may be politically convenient for some returning states to single out individuals as the primary target of return policies. As it is not within the returning state's power to rectify the recalcitrant behaviour of countries of origin, it turns to recalcitrant individuals. In doing so, it demonstrates to the domestic electorate that something is being done about the return problem. Even from an efficiency-oriented particularist perspective, however, such behaviour remains questionable.

The thrust of the above analysis is confirmed in an EU strategy document drafted by Austria: 'The speeding up of the voluntary return of illegal immigrants was as strikingly unsuccessful throughout Europe (although there were major repatriation initiatives in individual cases) as the steps taken to establish the widest possible network of readmission agreements [...]. A problem hardly referred to in the 1994 paper [the Commission Communication on Asylum and Migration Policies, GN] was the increasing refusal of a growing number of States of origin to take back their own nationals from the country which they had entered illegally'. ${ }^{787}$

What does this imply for the rejected protection seeker? In single cases, return may be facilitated through joint transport arrangements or coordinated pressure on third countries, but it is too early to assess the impact of the EU acquis on the probability of return. The importance return policies have acquired on the political agenda of the Member States is reflected by the number, but not the quality, of legal instruments

${ }^{787}$ Council of the European Union, Strategy paper on migration and asylum policy, Date unavailable, para. 20. This paper represents the second revision of the draft of 1 July 1998. 
dealing with return. The absence of an instrument laying down minimum standards of treatment for forcible removals is particularly striking. In other words, return is still a national affair. A rejected protection seeker would better look to the domestic authorities, and not to Brussels, when calculating the probability of return in her case.

\subsection{Intermediary Conclusion: Access to Protection in the EU}

European integration in the area of immigration and asylum suffers from a double fragmentation: one is institutional, the other normative, in nature.

Institutionally, immigration and asylum issues were fully exposed to the tension created by the two speeds and two pillars of integration. Consider the 1992 Maastricht treaty, which moved visa issues to the supranational first pillar, whereas asylum and migration issues were hosted in the intergovernmental third pillar. The normative tool-box of the third pillar was rather disappointing and a far cry from what the first pillar had on offer. Formally, this tension was mended with the 1997 Amsterdam Treaty, providing for a transfer of asylum and migration issues to the first pillar. However, both issues remained entangled in a strait-jacket of intergovernmental decision-making, at least for the duration of the transitional period. Effectively, a veto is retained for all Member States during this period. Therefore, it is questionable to celebrate the Amsterdam Treaty as a victory of supranationalism.

However, the potential of Amsterdam for overcoming material fragmentation should not be underestimated. It made binding EC instruments available in the field of asylum and migration and opened a window for judicial review by the ECJ. Amsterdam also succeeded with the integration of the avant-garde: the Schengen Group and its achievements were merged with the Union framework. Due to the special status of Denmark, the U.K. and Ireland, this did not mean the complete abolishment of two speeds, however.

Within the institutional world, the tendency is clear. Although a slow move towards limited supranationalism is taking place, it is hampered by the perseverance of veto and a variety of formal opt-outs. Still, the Community will remain unable to react with the same swiftness as a state or a minor state grouping. 


\section{CHAPTER 7}

The regulation of competencies through the treaties is not the sole factor impacting the institutional setting. The circle of participants, determined by the ongoing enlargement process, must be regarded as equally important. Although the candidates are required to implement the EU acquis as it stands on the day of accession, they will, of course have a voice in decisions taken after that day. It is too early to predict exactly how this reconfiguration will affect the efficiency and profundity of co-operation. But the variables are clear. To what extent will Member States succeed in the abolishment of the remaining veto on migration and asylum issues during the five-year period? Which candidates shall be admitted? Will they be admitted under or after the veto era? Undoubtedly, the enlargement process has a potential for exacerbating the existing fragmentation tendencies.

Apart from the institutional setting, fragmentation persists in the normative world as well. If we look into the topics dealt with at the multilateral level, the following pattern emerges. First, the period 1985-92 stood for a rather successful development of deflection tools. ${ }^{788}$ From 1992 onward, deflection was continuously refined, but saw few innovations ${ }^{789}$. This made room for the discussion of protection-related issues such as temporary protection, burden-sharing, and, most radically, the intervention into root causes. ${ }^{790}$ However, it is striking that fourteen years of cooperation yielded only four major instruments of binding nature laying down specific rules for the management of migration and asylum. ${ }^{791}$ All of them deal with control rather than protection, and all of them have an impact on the protection seeker's access to territory: 1990 saw the conclusion of the Schengen and Dublin Conventions, setting the overall framework for

${ }^{788}$ Apart from the Schengen and Dublin Conventions, the non-binding 1992 London Resolutions should be named in this context.

789 In this context, the Pre-frontier Joint Position is relevant.

790 Those debates found their expression inter alia in the 1995 Resolution on Burden-sharing (see text accompanying note 882 below), the 1996 Refugee Joint Position (see text accompanying note 719 below), the Commission Proposal on Temporary Protection and Solidarity (see text accompanying note 910 below), and, finally, the discussions on the root causes of migration within the HLWG (see text accompanying notes 762 and 763 below).

791 We are not considering Joint Positions and Joint Actions here, as the scope of their binding force is very limited. See chapter 1.4.2.6 on legal effects of Joint Positions and Joint Actions. Further, we disregard from the binding Decisions by the Schengen Executive Committee, as these are intrinsically linked to the implementation of the Schengen Convention. 
deflecting unauthorised migrants and allocating asylum claims. Furthermore, in 1995, the Council issued a regulation determining those countries whose nationals must be in possession of a visa when crossing the external borders of the Union..$^{792}$ And, finally, in 1997, the Member States agreed on a binding instrument governing procedures-the Spanish Protocol. The discussion of protection-related issues by EU institutions did not yield a single binding instrument. In a later chapter, we shall subject central elements of these four instruments to closer scrutiny with a view to their conformity with international law. ${ }^{793}$

The divide between protection and control is further exacerbated by the schedule set for future measures in the field of asylum and immigration. Both the Amsterdam Treaty itself and the Action Plan drawn up by the Council prioritise mostly control-oriented measures. ${ }^{794}$ Thus, control continues to enjoy a first mover's advantage over protection.

Why is this so? We recall that one determinant of protection systems has hitherto not been dealt with: the availability of burden-sharing. In the following chapter, we shall look into the way burden-sharing is regulated in international law, and the law of the European Union. As shall emerge, this determinant is the key to understanding the persistent divide between protection and control, and, consequently, the perseverance of l'Europe à deux vitesses in the immigration and asylum area.

792 This instrument was replaced by a new one in 1999 , and is presently merged with the Schengen visa livi. See text accompanying note 455 below.

793 See chapter 12 below.

794 We recall that Art. 63 TEC exempted measures on burden-sharing, on long-term visas and residence permits and on mobility rights for legally present aliens from the mandatory five-year time-frame. See also paras 36, 37 and 38 of the Action Plan. 